\title{
My Healthy Brain: Rationale and Case Report of a Virtual Group Lifestyle Program Targeting Modifiable Risk Factors for Dementia
}

\author{
Ryan A. Mace ${ }^{1,2} \cdot$ Sarah W. Hopkins ${ }^{1} \cdot$ Gretchen O. Reynolds $^{2,3} \cdot$ Ana-Maria Vranceanu $^{1,2,4}$
}

Accepted: 4 January 2022 / Published online: 25 January 2022

(c) The Author(s), under exclusive licence to Springer Science+Business Media, LLC, part of Springer Nature 2022

\begin{abstract}
Nearly half of dementia cases may be explained by modifiable lifestyle risk factors. Multidomain interventions are needed to bypass cognitive decline (CD) and aging-related barriers to sustained healthy lifestyles in at-risk older adults. We iteratively developed My Healthy Brain, a group-based lifestyle program ( 8 weeks, 90 min sessions) delivered via live video that applies behavioral principles to target multiple risk factors for dementia. We describe the program structure, virtual delivery, and outcomes for a group of older adults with subjective $\mathrm{CD}$ or mild cognitive impairment and lifestyle risk factors (e.g., sedentary, poor sleep or diet). We also conducted a group exit interview to qualitatively assess participant experiences and elicit feedback to improve My Healthy Brain. This case report demonstrates that delivering evidence-based brain health education and behavior change skills in a group setting via live video is feasible, acceptable, and has the potential to improve lifestyle, cognitive, and psychosocial outcomes in older adults with CD.
\end{abstract}

Keywords Lifestyle $\cdot$ Dementia $\cdot$ Cognitive impairment $\cdot$ Telehealth $\cdot$ Case study

\section{Introduction}

Dementia and cognitive decline $(\mathrm{CD})$ are a growing priority as the global population ages (Brookmeyer et al., 2007; Larson et al., 2013). An estimated 50 million people have dementia and nearly 10 million cases are diagnosed every year worldwide (World Health Organization, 2017). Prior to developing dementia, many older adults experience subjective CD (self-reported cognitive concerns in the absence of deficits on formal testing) (Jessen et al., 2014) or mild cognitive impairment (objective decrease in cognitive performance on testing that surpasses normal aging but does not significantly impact daily functioning) (Allan et al., 2017). Although medications (e.g., cholinesterase inhibitors)

Ana-Maria Vranceanu

avranceanu@mgh.harvard.edu

1 Integrated Brain Health Clinical and Research Program, Department of Psychiatry, Massachusetts General Hospital, Boston, MA, USA

2 Harvard Medical School, Boston, MA, USA

3 Brigham and Women's Hospital, Boston, MA, USA

4 Integrated Brain Health Clinical and Research Program, One Bowdoin Square, Suite 100, Boston, MA 02114, USA temporarily treat cognitive symptoms, no biomedical treatments can prevent or cure dementia (Mehta et al., 2017; Raina et al., 2008; Sink et al., 2005). The sensitivity of biomarkers is also limited, as the detection of genetic risk or pathology on neuroimaging does not fully explain the progression from CD to dementia (Ewers et al., 2011; Jansen et al., 2015). Novel non-pharmacological interventions are needed to help older adults reduce dementia risk factors and promote independence while cognitive symptoms are in their earliest stage.

Approximately $40 \%$ of dementia cases may be explained by modifiable lifestyle risk factors including lack of exercise, poor diet, inadequate sleep, elevated alcohol and tobacco use, and limited social and mental stimulation (Ashford \& Mortimer, 2002; Barnes \& Yaffe, 2011; Slooter et al., 1998). The odds of developing dementia increase with the number of lifestyle risk factors in a dose-response relationship (Lourida et al., 2019; Whitmer et al., 2005). Modifying these lifestyle behaviors can also protect against dementia in older adults with $\mathrm{CD}$ that have additional genetic, cardiovascular, or neurodegenerative risk factors (Lourida et al., 2019; Rabin et al., 2019). The benefits of a healthy lifestyle accumulate with aging (Ahlskog et al., 2011; Barnes \& Yaffe, 2011), and lifestyle factors are a feasible and cost-effective option for reducing one's own risk for dementia (Clark et al., 
2012). Yet, this research has not translated to evidencebased programs for older adults with early $\mathrm{CD}$, who struggle to adopt lifestyle behaviors on their own (Cations et al., 2018). There is a clear need for multidomain interventions that teach behavior change skills and bypass aging and CDrelated barriers to sustained healthy lifestyles.

In response to this gap, our team iteratively developed My Healthy Brain, a group-based lifestyle program (8 weeks, 90 min sessions) that applies behavioral principles to target multiple risk factors for dementia within one intervention. My Healthy Brain was informed by similar lifestyle trials (McMaster et al., 2020; Ngandu et al., 2015; SPRINT MIND Investigators for the SPRINT Research Group et al., 2019) and our team's experience adapting interventions for neurological populations (Greenberg et al., 2019; Mace et al., 2021; Mace et al., 2020; Vranceanuet al., 2018), and feedback from older adults with CD. My Healthy Brain combines evidence-based skills from cognitive-behavioral therapy and motivational interviewing (Barrett et al., 2018) with education on dementia risk factors (Livingston et al., 2020; Sabayan \& Sorond, 2017; Xu et al., 2015) to promote sustained engagement in a brain healthy lifestyle with aging (Belleville et al., 2020) (Fig. 1). We conceputalized My Healthy Brain based on the Scaffolding Theory of Aging and Cognition (Reuter-Lorenz \& Park, 2014), which posits that lifestyle behaviors serve as "neural compensatory scaffolding" factors that optimize brain structure and function, which in turn preserves cognitive functioning with aging.

Following the NIH Stage Model (Onken et al., 2014), we developed My Healthy Brain and conducted a non-randomized feasibility open pilot (NIH Stage 1a) with older adults $(N=24)$ referred by their neurologist for $\mathrm{CD}$ and lifestyle risk factors Mace et al., 2021. My Healthy Brain demonstrated preliminary feasibility and improvements in primary lifestyle outcomes as well as secondary outcomes of self-determination and subjective wellbeing when delivered in person. Despite high program adherence and program satisfaction, qualitative feedback from participants revealed several barriers to in-person participation (e.g., transportation, scheduling, COVID-19) that hindered progress toward their lifestyle goals. Our prior work suggests that older adults are motivated to learn Zoom to promote cognitive health (Doorley et al., 2021), highlighting the potential for delivering the My Healthy Brain via live video.

In this case report, we describe the first entirely virtual clinical group of My Healthy Brain INTERVENTION for older adults with subjective $\mathrm{CD}$ or mild cognitive impairment and lifestyle risk factors for dementia. Our goal was to showcase the program rationale, session structure, virtual delivery of the program skills, individualized goal setting, home practice adherence, and associated improvement in lifestyle and psychosocial outcomes. We also conducted post-intervention qualitative exit interviews to illustrate patient experiences in the program. In doing so, we aimed to demonstrate how clinicians may overcome common challenges to promoting brain health in this older adult population. We discussed the implications of our findings for enhancing My Healthy Brain and study procedures for future clinical groups and research trials.

\section{Methods}

\section{Study Design}

We conducted a single virtual clinical group of My Healthy Brain with a qualitative exit interview. Our methodology follows the procedures reported in the My Healthy Brain development study (Mace et al., 2021). We adapted the program and delivery based on our published protocol for conducting virtual assessments and lifestyle interventions via Zoom (Mace et al., 2020), which have been succesful in other older adult populations (Doorley et al., 2021). Prior to the group, we met regularly with interdiciplinary clinical staff from the Osher Center for Integrative Medicine at the Brigham and Women's Hospital to discuss efficient referrals to this virtual program.

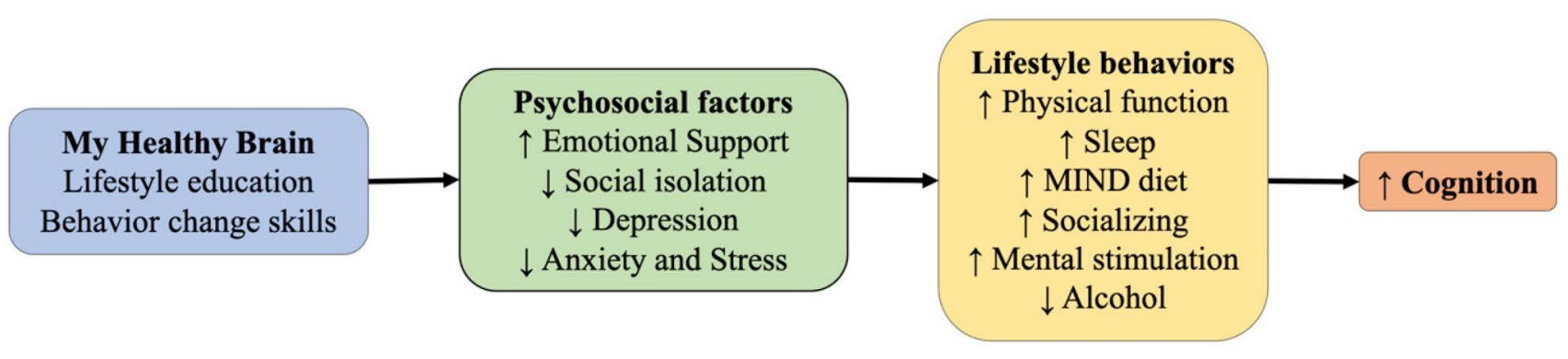

Fig. 1 Conceptual model of multidomain intervention targeting modifiable risk factors of brain disease and optimizing cognitive function with aging 


\section{Participants}

The Massachusetts General Hospital Human Research Committee has approved the procedures (IRB \# 2020P003067 and 2020P004087). Patients were referred to My Healthy Brain by their medical provider at Brigham and Women's Hospital and the Osher Center for Integrative Medicine. We also distributed program recruitment flyers and presented My Healthy Brain to interdisciplinary teams to broaden our inclusion of patients at the hospital. Trained study staff conducted initial phone screenings and a licensed clinical health psychologist reviewed all cases prior to study enrollment.

Our eligibility criteria were consistent with the My Healthy Brain development study (Mace et al., 2021) and similar lifestyle programs for CD (Andrieu et al., 2017; Lam et al., 2015; Ngandu et al., 2015; SPRINT MIND Investigators for the SPRINT Research Group et al., 2019). Inclusion criteria were (1) age $\geq 60$; (2) English fluency/literacy; (3) subjective cognitive concerns (Jessen et al., 2014) or mild cognitive impairment identified by the referring provider (Allan et al., 2017); (4) patient self-reported interest in modifying at least one lifestyle risk factor for dementia targeted in My Healthy Brain (physical inactivity, poor diet, inadequate sleep, elevated alcohol and tobacco use, medication nonadherence, limited intellectual and social stimulation) (Sabayan \& Sorond, 2017); and (5) willingness/ability to participate in the 8 -week group program via live video.

The exclusion criteria were (1) dementia; (2) medical illness expected to worsen in the next 12 months (e.g., cancer); (3) serious untreated psychiatric disorders (e.g., schizophrenia, bipolar disorder); (4) current substance abuse; (5) current suicidal ideation; and (6) current enrollment in another lifestyle modification program. Following procedures from our prior development study (Mace et al., 2021), the absence of dementia was confirmed by the referring medical provider and a review of the medical records. We excluded dementia because the program is designed for at-risk older adults with subjective or mild cognitive impairment. We also wanted to ensure that participants have a thorough understanding of the project and be able to meaningfully participate in session and complete weekly homework. We excluded suicidality and serious medical or mental illnesses due to requiring higher levels of care than the group can provide. Current substance abuse and participation in a similar program represent treatment confounds.

We included older adults with subjective and mild cognitive impairment because both are (1) common in clinics that treat older patients (Rosenbloom et al., 2016), (2) risk factors for future CD (Jessen, 2014; Langa \& Levine, 2014; Verlinden et al., 2016), and (3) potentially modifiable through improvements in brain health via lifestyle change (Cadar et al., 2012). This decision was also informed by our similar intervention development studies that did not find differences in outcomes or benefit from program skills by type of $\mathrm{CD}$ based on data and clinician observations (Doorley et al;, 2021; Mace et al., 2020).

\section{Procedures}

We screened 20 potential participants with the goal of forming a group size of 10-12 to account for dropout. Of these, 3 declined and 6 had scheduling conflicts and were put on hold to participate in the next round of groups. We enrolled and completed informed consent with 11 participants. Three participants did not attend any sessions (scheduling conflicts) and 1 participant dropped after attending the first session (to address depression and loneliness in individual therapy). The remaining 7 participants completed the program (6/7 attended $\geq 6$ sessions).

One week prior to the first session, the group leader emailed participants all study materials: (1) 90-min Zoom calendar appointments for the 8 consecutive weeks of My Healthy Brain, (2) tips for using Zoom in clinical groups, (3) an electronic copy of the treatment manual, and (4) a secure REDCap link to complete the baseline self-report assessments. We followed our published protocol for conducting virtual assessments and lifestyle interventions via Zoom (Mace et al., 2020) and guidelines to help older adults use the technology (Tsai et al., 2017). The research coordinator contacted all participants to gauge familiarity with Zoom, assist installation and login, and teach the functions relevant to the group: gallery view to see all participants, camera mode to enable video, and mute to limit noises in their environments when not speaking. We encouraged participants to contact the group leader for technological assistance at any time. Three participants required assistance from family to log into the weekly Zoom sessions.

Participants completed self-report measures of lifestyle and psychosocial function online via REDCap at baseline and post-intervention. The research coordinator contacted participants to administer assessments via phone when necessary and attempts to collect this data were discontinued after three reminder emails. For this case report, we compiled data from clinical notes, participant email correspondence, weekly home practice, electronic medical records, and referral sources.

\section{My Healthy Brain Program}

A clinical neuropsychologist with clinical and research expertise in aging and brain health and a clinical psychology doctoral student co-led the 8-week My Healthy Brain group program via Zoom. Each session is an interactive group discussion $(90 \mathrm{~min}$ ) facilitated by the group leaders 
that involves a review of previous material (10\%), problem solving of barriers to adherence (15\%), education on lifestyle risk factors for dementia (30\%), and behavior change skills with weekly goal setting (45\%). Participants received feedback from the clinicians and group members on setting weekly SMART goals (White et al., 2013) (i.e., goals that are Specific, Measurable, Attainable, Relevant, and Time bound) to improve the lifestyle factors identified by their referring provider and deemed personally significant. The study clinicians sent participants weekly email reminders about the group session and encouraged them reply with an update on their SMART goal and progress. Reviewing the manual and taking notes was optional but encouraged to improve recall of material and individualized goals between sessions. The clinician wrote weekly progress notes for each participant and provided weekly supervision to the doctoral student for treatment fidelity.

Table 1 outlines the topics and corresponding skills for each session of My Healthy Brain. The first session provides an overview of brain health, the importance of lifestyle for $\mathrm{CD}$ and dementia prevention, and setting individualized SMART goals. The subsequent sessions target the lifestyle risk factors for dementia consistently identified in the brain health literature (Andel et al., 2008; Barnes \& Yaffe, 2011; Baumgart et al., 2015; Geda et al., 2010; Hamer \& Chida, 2009; Xu et al., 2015): sleep (Session 2), physical activity (Session 3), nutrition (Session 4), medication adherence/ substance use (Session 5), social stimulation (Session 6), and mental stimulation and cognitive reserve (Session 7). My Healthy Brain includes skills to overcome common barriers to modifying each of the lifestyle behaviors, such as enhancing motivation, cultivating self-compassion to cope with setbacks, setting manageable goals (e.g., pacing physical activity), tracking progress (e.g., using activity logs), managing stressors and urges that lead to unhealthy habits (e.g., for diet and substance use), and addressing interpersonal difficulties. The final My Healthy Brain session includes a program review and development of a valuesbased plan to maintain healthy lifestyles.

\section{Quantitative Measures}

All self-report assessments were reliable and valid, and align with similar lifestyle programs (Andrieu et al., 2017; Claudia et al., 2020; Lam et al., 2015; Ngandu et al., 2015; SPRINT MIND Investigators for the SPRINT Research Group et al., 2019). Full details on the self-reports can be found in the My Healthy Brain development study (Mace et al., 2021). We assessed program credibility and expectancy prior to My Healthy Brain using the Credibility and Expectancy Questionnaire (CEQ-6; Devilly \& Borkovec, 2000). We assessed program satisfaction after completing My Healthy Brain using the Client Satisfaction Questionnaire (CSQ-3; Attkisson, 1996). On the remaining self-report assessments below, we reported the pre-intervention (i.e., to indicate baseline severity level) and change score (i.e., to indicate progress during My Healthy Brain). We indicated when pre-post differences exceeded the reliable change based on available norms (Jacobson \& Traux, 1991). We interpret the results in

Table 1 My healthy brain group session topics and skills

\begin{tabular}{|c|c|c|}
\hline Session & Topic & Skills \\
\hline 1 & Brain health and habit formation & $\begin{array}{l}\text { Education: modifiable lifestyle factors, brain health and disease } \\
\text { Habit change skills: identifying and setting SMART goals, motivation rulers, problem-solving bar- } \\
\text { riers (e.g., stressors), self-monitoring }\end{array}$ \\
\hline 2 & Sleep & $\begin{array}{l}\text { Education: sleep quality and brain health, sleep hygiene } \\
\text { Habit change skills: sleep log, stimulus control, sleep restriction }\end{array}$ \\
\hline 3 & Physical activity & $\begin{array}{l}\text { Education: physical activity and brain, risk of sedentariness } \\
\text { Habit change skills: activity pacing, behavioral activation, pairing activity with socializing, } \\
\text { problem-solving barriers }\end{array}$ \\
\hline 4 & Nutrition & $\begin{array}{l}\text { Education: MIND diet and brain health, MyPlate (food groups and portions) } \\
\text { Habit change skills: awareness of hunger/fullness cues, visualizing portion size, food log, environ- } \\
\text { mental modifications }\end{array}$ \\
\hline 5 & Medication and substance use & $\begin{array}{l}\text { Education: substance use (tobacco, alcohol), medical care, and brain health } \\
\text { Habit change skills: medication log, effective communication with doctors, coping with stressors } \\
\text { that increase urges to use alcohol or tobacco }\end{array}$ \\
\hline 6 & Social relationships & $\begin{array}{l}\text { Education: socializing and brain health, social support types } \\
\text { Habit change skills: interpersonal effectiveness, shared activity planning, reducing loneliness with } \\
\text { age, identifying social support network }\end{array}$ \\
\hline 7 & Building healthy brain reserve & $\begin{array}{l}\text { Education: brain reserve, neuroplasticity, cognitive domains } \\
\text { Habit change skills: developing compensatory strategies, increasing intellectual stimulation }\end{array}$ \\
\hline 8 & Enjoying a brain healthy lifestyle & $\begin{array}{l}\text { Education: maintenance and prevention planning, sustaining changes, review } \\
\text { Habit change skills: values identification, scheduling meaningful and pleasurable activities }\end{array}$ \\
\hline
\end{tabular}


the context of each cases' individualized goals and lifestyle risk factors.

We assessed CD symptoms with the 12-item Everyday Cognition Scale (eCog-12; Tomaszewski Farias et al., 2011) and the PROMIS Cognitive Function (Cella et al., 2010). Lifestyle measures included physical function with the PROMIS Physical Function (Rose et al., 2008) and exercise with the Godin Leisure-Time Exercise Questionnaire (GLQ; Amireault \& Godin, 2015); sleep with the Pittsburgh Sleep Quality Index (PSQI; Buysse et al., 1989); MIND diet with the Mediterranean Eating Pattern for Americans Screener (MEPA; Cerwinske et al., 2017); and alcohol use with the Alcohol Use Disorders Identification Test-Consumption (AUDIT-C; Bush et al., 1998). We also administered an 8 -item (range $=0-8$ ) checklist of Brain Health Behaviors $(B H B)$ to assess the presence (1 point) or absence (0 points) of lifestyle targets: increasing (1) exercise, (2) sleep, (3) MIND/Mediterranean diet, (4) cognitive stimulation, (5) socializing; and reducing (6) alcohol, (7) smoking, and (8) stress. We assessed stress with the 10-item Perceived Stress Scale (PSS-10; Cohen et al., 1983) and anxiety (v1.08a), depression (v1.08b), emotional support (v4a), and social isolation (v4a) with the PROMIS scales (Hahn et al., 2014; Pilkonis et al., 2011, 2014).

\section{Group Exit Interview}

We conducted an optional group exit interview with participants via Zoom (90 min) 1-week post-intervention. The study clinicians led the group exit interview according to guidelines for collecting valid qualitative data (e.g., Rubin $\&$ Rubin, 2005) and creating a comfortable environment for self-disclosure (Shaha et al., 2011). All participants had the opportunity to provide open-ended feedback on the program during the post-intervention REDCap that they might not have felt comfortable discussing during the group. We recorded and manually transcribed the exit interview.

Our multidisciplinary team developed a semi-structured exit interview script that explored 5 major topics: (1) overall experience in My Healthy Brain, (2) lifestyle changes that occurred during the program, (3) experience with Zoom, (4) impressions of the program skills, and (5) barriers and facilitators to participation. Additionally, we explored opinions on including mindfulness training and wearable devices in future versions of My Healthy Brain to address stress (e.g., Rachel case report) and difficulty self-monitoring lifestyle changes (e.g., Julia case report below). Both wearable devices and mindfulness, a practice of non-judgmental awareness of the present (Ludwig \& Kabat-Zinn, 2008), have the potential to promote healthier lifestyle choices and sustain behavior change in older adults (Brawley et al., 2003; Dutton, 2008; Geiger et al., 2016; Sullivan \& Lachman, 2017; Schuman-Olivier et al.,
2020) but have not been integrated in programs that target dementia risk factors.

We used rapid assessment procedures to analyze the focus group data consistent with established qualitative frameworks (Eaton et al., 2019; Gale et al., 2019; Renfro et al., 2021). Rapid assessment is a valid alternative to in-depth qualitative analysis to identify timely and actionable strategies to improve clinical programs (Hamilton \& Finley, 2019; Taylor et al., 2018). We created a summary template of each of the 5 a-priori exit interview topics. The study clinicians used the summary template to take notes during the exit interview and reflexively summarize main ideas directly after. All authors met to collaboratively discuss the summary until a consensus was reached for each topic. When available, we reported quotes from the cases that illustrate the five major exit interview topics.

\section{Results}

The 7 program completers ranged in age from 63 to 91 years ( $M=75$ years), were White and Non-Hispanic/Latino, and were balanced in terms of women $(n=4)$ and men $(n=3)$. Three participants were widowed, 3 were married, and 1 was separated/divorced. Three participants completed some college, 3 had college degrees, and 1 had a graduate/professional degree. Three participants had subjective cognitive concerns, 4 had mild cognitive impairment, and 1 participant was on the border between these diagnoses (pending neurologic follow-up evaluation scheduled after the program).

All 7 of the enrolled participants met our a-priori criterion for program completion (Mace et al., 2021) of attending at least 6 of the 8 sessions. Only 3 participants-"Rachel," "Emily," and "Julia"-completed the self-report outcome measures. Three participants did not complete the self-report measures because they were optional $(n=3)$. The remaining participant did not own a computer and was unable to complete the online survey on his phone. Consistent with the goal of this study, we focused our case report and exit interview results on the 3 participants with complete data to fully showcase program delivery. We also discuss the potential bias and implications of the missing data.

\section{Rachel}

Rachel was a 70-year-old, White, non-Hispanic, married woman with some college education and a retired teacher. She presented to the group program with concerns about memory and executive functioning difficulties over the past two years. Nineteen months prior to the group, Rachel underwent a neuropsychological evaluation which was largely unremarkable, though she continued in neurologic 
follow-up with concern for progressive cognitive decline. Her baseline CEQ score indicated low initial perceptions of the program's credibility (14) and low expectations for improving (8).

During the first session, she expressed concerns about cognitive decline ("I feel like my brain is becoming unraveled"), consistent with her clinically significant baseline PROMIS (28.8) and eCog-12 (2.6) scores. She had a growing recognition of how anxiety about forgetfulness and confusion negatively impacted her concentration: "I recognize that becoming stressed when I do something wrong is harmful to my thinking process in the moment. I was not aware that being stressed has long-term effects on my brain." She expressed interest in learning about brain health to optimize daily functioning and decrease stress.

Rachel set multiple lifestyle goals. She presented with high baseline levels of exercise $(\mathrm{GLQ}=15)$ and physical function (PROMIS =59), but wanted to set and adhere to clear exercise goals to keep herself accountable during the COVID-19 pandemic. She overcame these barriers by applying the SMART goal framework and seeking feedback from group members. By the end of the program, Rachel had incorporated walking and exercising in the pool three times a week for two consecutive weeks. Rachel also learned to track her daily food intake and nutrition using a MIND diet $\log$ in the treatment manual. Greater awareness of her eating habits and food choices appeared to promote self-efficacy and reinforce motivation for healthy eating. She also started to complete mentally stimulating games by downloading a popular brain exercise application on her smartphone.

Rachel experienced significant life stressors during the program (pre PSS-10 $=22$, moderate stress). Rachel learned about the potential of self-compassion to sustain her motivation when she did not meet her lifestyle goals or forgot to track her food intake. Using self-compassion, Rachel recommitted to her MIND diet goals and food intake tracking the following week without getting discouraged ("Especially during the pandemic, I was eating unhealthy foods and too much of them. This class helped me get back on a healthier eating path and 'back on the wagon"'). At times, Rachel confused the My Healthy Brain program with her other appointments. Through validation from clinicians, Rachel became more willing to adopt compensatory strategies such as to-do lists to support daily memory rather than avoiding these strategies due to anxiety about cognitive decline ("I felt like I was giving in to whatever is happening to my brain but now I am open to helping my brain in whatever ways I can"). By the end of My Healthy Brain, Rachel developed a growing interest in practicing self-compassion when she fell short of her goals and learning about mindfulness to cope with unexpected life stressors.

Rachel reported high satisfaction with the program $(\mathrm{CSQ}=8)$. She endorsed reductions in $\mathrm{CD}$ symptoms
$(\Delta$ PROMIS $=+11.2$, reliable improvement; $\Delta$ eCog$12=-0.4)$. On lifestyle measures, she reported increased sleep quality ( $\Delta \mathrm{PSQI}=-1$ ) and engagement in the MIND diet, socializing, cognitive stimulation (BHB; pre $=5, \Delta=+3$ ). Exercise ( $\Delta \mathrm{GLQ}=0$ ) and physical function $(\Delta$ PROMIS $=0)$ did not change. Rachel did not set goals for alcohol during the program and her use did not change (AUDIT-C; pre $=3, \Delta=0$ ). In contrast with the improvements in eating habits reported during the group, her MIND diet adherence minimally decreased (MEPA; pre $=9, \Delta=-1$ ). On psychosocial measures, she reported improvements in emotional support (PROMIS; pre $=50.3$, $\Delta=11.7$, reliable improvement), stress (PSS-10 $\Delta=-10$, reliable improvement) and depression (PROMIS; pre $=55.3$, $\Delta=-1.2$ ). Social isolation slightly increased (PROMIS; pre $=50, \Delta=+1.6$ ) and anxiety did not change (PROMIS; pre $=59, \Delta=0$ ).

\section{Emily}

Emily was an 80-year-old, White, non-Hispanic, widowed woman with a college degree who retired as a home health care nurse. She presented to group with concerns about mild impairment in memory recall and word-finding for approximately 2.5 years leading up to her participation in the group, as well as a family history of Alzheimer's disease. Her CD symptoms were also evident on baseline selfreports (PROMIS $=39.1$, eCog-12 $=2.5$ ). She completed formal neuropsychological testing several months prior to the group, which was largely within normal limits. Her primary goal was to learn more about brain health and prevent future $\mathrm{CD}$. She was also interested in building upon skills that she acquired in prior cognitive rehabilitation programs. Similar to Rachel, Emily's baseline CEQ indicated low initial perceptions of the program's credibility (11) and low expectations for improving (10).

Emily wanted to improve her baseline physical activity (PROMIS $=43$, low), exercise $(\mathrm{GLQ}=3$, low), and MIND diet adherence (MEPA $=9)$. The clinicians helped Emily to prioritize and set SMART goals each week to promote sustainable habit formation. Emily's physical activity had previously involved socializing (e.g., at the gym, ski trips), which was no longer possible due to COVID-19 restrictions. She learned to expand her physical activities by focusing on a sense of enjoyment, accomplishment, and values (e.g., being in nature) in the activities she chose. Emily was motivated by tracking her daily physical activity using a log in the treatment manual. Emily also used the tracking logs to explore her dietary habits and learned to notice her hunger/fullness cues. This helped Emily manage portion sizes and choose healthier food substitutions consistent with the MIND diet ("When I pick up something to eat, I know whether it's something that is good for me."). 
Emily reported high satisfaction with the program $(C S Q=10)$. She reported a small reduction in CD symptoms $(\Delta$ eCog-12 $=-0.4, \Delta$ PROMIS $=+0.10)$. On lifestyle measures, she reported increased physical function $(\Delta$ PROMIS $=+16.0$, reliable improvement) but no changes in exercise $(\Delta \mathrm{GLQ}=0)$. She reported greater engagement in socialization and cognitive stimulation $(\mathrm{BHB}$; pre $=6$, $\Delta=+2$ ). Emily did not report changes in sleep (PSQI pre $=2, \Delta=0$ ) and alcohol use (AUDIT-C pre $=2, \Delta=0$ ), both of which were not problematic at baseline. In contrast with her self-report during the group, her MIND diet adherence slightly decreased $(\Delta \mathrm{MEPA}=-1)$. On psychosocial measures, she reported improvements in stress (PSS-10; pre $=15, \Delta=-8$, reliable improvement), emotional support (PROMIS; pre $=41, \Delta=+5.8$, reliable improvement), and social isolation (PROMIS; pre $=56, \Delta=-4.1$ ). Depression was low at baseline and slightly increased (PROMIS; pre $=43.3, \Delta=+2.7$ ), and anxiety did not change (PROMIS; pre $=54.7, \Delta=0$ ).

\section{Julia}

Julia was an 84-year-old, White, non-Hispanic, widowed woman with some college education, who did not disclose her employment history. She presented to group with a diagnosis of mild cognitive impairment per neurologic workup (and confirmed by formal neuropsychological evaluation completed two months after the group). Julia reported fewer baseline cognitive symptoms on the self-reports than the other cases (PROMIS $=50$, eCog-12=1.7), suggesting reduced insight. In addition to learning more about brain health, Julia was interested in improving her memory and organization, forming social connections, and "staying vital." She felt her thinking was "not as sharp" as in the past, noting forgetfulness and disorganization. She reported high perceptions of the program's credibility (24) and high expectations to improve (34) on the CEQ.

Her weekly SMART goals primarily related to exercise $(\mathrm{GLQ}=24)$ and implementing organizational systems (calendar/to-do list). She enjoyed walking with friends and working with a personal trainer but did not identify as "an exercise person." To integrate her calendar use and exercise goals, the group encouraged her to schedule regular walks on her calendar. She met her walking goal and resumed sessions with a personal trainer during the group but struggled to use her calendar regularly. In contract with the other two cases, she did not send weekly email updates of goal progress and at times forgot her weekly goal, despite her motivation and interest in developing this habit.

Julia also set SMART goals related to diet $(\mathrm{MEPA}=12)$ and social support (PROMIS =38). She modified her initial goal to limit rather than eliminate bread (she tended to be "all-or-nothing" with food) and succeeded in meeting this goal with the support of her daughter. For social support, she connected with friends outdoors and by phone, which was helpful for her to cope with isolation experienced during COVID-19.

Julia endorsed organizational challenges, such as difficulty using a calendar, taking notes, and organizing her treatment manual, which interfered with her weekly SMART goals. Julia succeeded in setting and refining SMART goals by: (1) identifying motivational factors (e.g., social support and accountability) and (2) setting more realistic, flexible goals. She may have benefitted from additional support (daughter, clinician check-ins), structure (notetaking in a physical copy of the treatment manual), habit-stacking (linking goals with established behaviors), and more targeted reminders. During the final session, she expressed interest and motivation to continue with goals related to exercise, diet, and social support, including regular walking (at least $4 \times /$ week) and limiting her intake of bread by keeping it out of the house. She also set a goal of choosing a new book to read to continue to build cognitive reserve and keep her brain sharp, which she wrote down as a reminder.

Julia reported high satisfaction with the program $(\mathrm{CSQ}=12)$. Julia reported a decrease in $\mathrm{CD}$ symptoms $(\Delta$ PROMIS $=+9.1$, reliable improvement; $\Delta$ eCog$12=+0.3)$; however, her baseline scores were likely an underestimate of CD symptoms given her mild cognitive impairment diagnosis. On lifestyle measures, she reported improvements in sleep quality (PSQI; pre $=8, \Delta=-1$ ), sleep hygiene (BHB, pre $=5, \Delta=+1$ ), alcohol use (AUDIT$\mathrm{C}$; pre $=2, \Delta=-1)$, and exercise $(\Delta \mathrm{GLQ}=+6)$, diet $(\Delta$ MEPA $=+1)$. Physical function $(\Delta$ PROMIS $=0)$ did not change. On psychosocial measures, she reported improvements in stress (PSS-10; pre $=11, \Delta=-9$, reliable improvement), emotional support ( $\Delta$ PROMIS $=+1.2$ ), and depression (PROMIS; pre $=55.3, \Delta=-5.4$, reliable improvement). Social isolation worsened (PROMIS; pre $=43.2, \Delta=+12.4$, reliable decline), which conflicted with her in-group report of connecting with friends and learning to cope with separation during COVID-19. She did not complete the PROMIS anxiety.

\section{Group Exit Interview}

The cases had positive overall impressions of the program and reported that it met their brain health needs. Rachel described "having a plan to follow now" and Emily said that the group "fit my needs at the moment." They enjoyed the length, session duration, group structure, weekly home practice, and treatment manual, though recommended that we offer a physical copy. The cases also had positive experiences with Zoom because it minimized travel, was easy to 
use, and offered flexibility with scheduling. They wanted greater clarity on the recruitment procedures and program components. For example, Rachel was confused about why she was referred to the program because her doctor never discussed the referral, which dampened expectations ("I wasn't sure why I was asked to be in the program, so I didn't know what I was supposed to get out of it").

The cases endorsed high satisfaction with the brain health education and behavior change skills. In fact, they wished that the program contained more in-depth education, such as review of the neuroscience of how lifestyle behaviors support brain health. The cases reported improvements in lifestyle and cognition, as evidenced by feedback from friends or family. For example, Julia said that "I'm exercising and walking more... I hired a trainer two times per week. I'm seeing the mental benefit." All three cases observed improvements in mood and socializing, which increased their motivation to sustain their goal progress. Program facilitators included: reminders, self-monitoring logs, setting shared goals with other members or friends/family, notetaking, accountability in group, and pairing goals with meaningful activities. Julia attributed her "walking success" to "the weekly connection of having consistent meetings that contributed to my mood." Lack of time and forgetfulness (e.g., forgetful of goals set in group) were the most common barriers. Despite the social support from the group, several participants reported that isolation during COVID19 decreased motivation (Emily: "I wasn't able to go to the $\mathrm{Y}[\mathrm{MCA}] \ldots \mathrm{I}$ like the social interaction involved in being in a facility").

Finally, the cases provided feedback to further enhance My Healthy Brain. Julia was familiar with mindfulness from family, and Emily identified its benefits on mental health. Julia described mindfulness, which she learned from her daughter, as: "sitting, staying quiet, and concentrating on what you're doing... it really makes life easier." The cases expressed interest in learning mindfulness during each of the weekly sessions and believed that guided meditations recorded by clinicians would facilitate home practice. They also shared favorable views of using wearable devices to monitor lifestyle changes. Emily had experience using a wearable device (e.g., Fitbit) and believed it would be motivating and reinforcing ("I like smart watches. They are motivating and give me natural goals to meet each day."). The other cases agreed with its benefits of behavior change but had concerns about accuracy of the data.

\section{Discussion}

In this group case report, we described the rationale and virtual delivery of My Healthy Brain, a multidomain lifestyle program targeting risk factors for dementia. The case reports, self-report measures, and group exit interview illustrate the impact of the program on a group of older adults at risk for dementia based on subjective or mild cognitive impairment and one or more unhealthy behaviors identified by their referring provider. The cases had strong attendance and adherence to home practice, reported excellent satisfaction, and shared favorable views of the program during the exit interview.

Participant engagement in the virtual My Healthy Brain support the acceptability and appropriateness of the program for our target population via this modality. This is notable given population-specific barriers, such as increased CD and functional dependence with aging, that can interfere with adherence to group programs and lifestyle behavior change (Mace et al., 2020). Based on the exit interviews, Zoom reduced the burden of participating in the group and fostered social connections during COVID-19. Attendance was high and Julia was the only participant among the 3 cases that required additional assistance with Zoom. This suggests that the Zoom training with the research coordinator and ongoing technological assistance from study clinicians was effective. To further support participants like Julia, programs can allot time at the beginning of each session to overcome technological challenges that emerge. We also recommend that teams use a combination of evidence-based skills for facilitating older adults' use of technology. These include leveraging social support (Barnard et al., 2013), providing reassurance, linking to personal relevance (Chaffin \& Harlow, 2005; Merriam et al., 2012), and allowing time for selfdirected learning and experimentation to develop confidence (Tsai et al., 2017).

Each case improved on one or more of their goals for the program, including cognition (Rachel, Emily), physical function (Emily), exercise (Julia), and MIND diet (Julia). Additionally, increased sleep, socializing, and cognitive stimulation were endorsed by at least two of the cases. Participants did not set goals for alcohol use and baseline AUDIC-C scores were low, which may explain the limited changes. The lifestyle changes found on the self-reports are similar in magnitude to the effects reported in prior trials (Andrieu et al., 2017; Heyn et al., 2004; Lam et al., 2015; SPRINT MIND Investigators for the SPRINT Research Group et al., 2019). Overall, the cases' goals were consistent with the findings on self-report assessments. The case reports illustrate how clinicians can use a combination of weekly monitoring, planning, and providing personalized feedback to reinforce individualized lifestyle goals that are best for each patients' brain health (Janssen et al., 2013; Tuso, 2015).

We also observed improvements in psychosocial functioning, notably with stress and emotional support. Prior multidomain lifestyle programs did not target psychosocial outcomes or reported no effects (Advocat et al., 2016). 
Participants attributed improvements in mood to cultivating a more active lifestyle that is personally meaningful. Two of the cases prioritized increasing social interactions and all group members received peer support, which likely promoted emotional functioning particularly during the COVID-19 pandemic. Additionally, participants practiced communication skills and learned about the detrimental effects of chronic stress and social isolation on the brain. Increasing awareness of modifiable risk factors and developing behavior change skills may have also provided participants with a newfound sense of control over their brain health.

Our study has several important limitations that highlight opportunities to improve My Healthy Brain. First, case reports are not generalizable and the participants, while consistent with referrals at our medical center, are not representative of the older adult population with CD (Nissen \& Wynn, 2014). Second, the cases reported lowtreatment credibility and expectancy at baseline, possibly due to family history or personal experience with progressive CD (Schulte, 2008), which can dampen outcomes if unaddressed (Constantino et al., 2011; Goossens et al., 2005). During the exit interviews, several participants described the recruitment and enrollment process as confusing, which may have reduced program credibility. We also lost participants after enrollment due to scheduling conflicts $(n=3)$ and treatment for depression $(n=1)$. Our results highlight the need to develop patient-friendly recruitment materials, clarify program expectations during enrollment, train staff to effectively communicate with the target population, and form partnerships with staff to smooth the integration of procedures within the clinic flow. In a subsequent study, we will conduct focus groups with medical stakeholders to obtain actionable suggestions to further identify and address barriers to implementing the program in academic medical centers. Third, to address the difficulty with self-monitoring and adhering to lifestyle goals (e.g., Emily and Rachel), we will explore the potential of wearable trackers to monitor and reinforce behaviors in My Healthy Brain. Fourth, participants agreed on the potential to incorporate mindfulness into My Healthy Brain sessions to enhance awareness and better tolerate unhealthy habits that can derail lifestyle goals (e.g., Julia). Finally, 4 of the 7 participants did not complete the self-report measures due to opting out and technological barriers. The 3 cases represented a wide range of clinical challenges, cognitive abilities (subjective and mild cognitive impairment), and lifestyle goals. Nevertheless, we cannot rule out the possible influence of selection bias because the participants who responded may have been particularly motivated. We will reduce missing data in future groups by providing education on the importance of the selfreports for tailoring intervention delivery based on individualized needs. We will also increase the options (e.g., phone administered, mailing physical copies) and level of support (e.g., study staff, family members) for completing the self-reports.

The U.S. health care system must arm medical providers with lifestyle and risk-reduction strategies to address the growing prevalence of dementia. This case report demonstrates that delivering evidence-based brain health education and behavior change skills in a group setting via live video is feasible and acceptable for older adults with CD. We illustrated how My Healthy Brain can overcome clinical challenges in this population by showcasing the delivery of skills, individualized goal setting, group accountability and emotional support, and adherence to home practice. The group's experience during the program and the exit interview provided valuable information to enhance My Healthy Brain for future trials. Next, we will conduct a live video feasibility RCT of the enhanced My Healthy Brain versus a time- and attention-matched education control (Health Enhancement Program; Mahaffey et al., 2020) to inform efficacy testing (NIH Stage II). Long-term, My Healthy Brain delivered via live video has the potential to promote sustained lifestyle changes and associated reductions in dementia risk factors in aging populations by teaching mindfulness and behavior change skills that can last a lifetime.

Acknowledgements The authors would like to thank the Osher Center for Integrated Medicine at Brigham and Women's Hospital and patients for supporting this research.

Author Contributions RAM oversaw data collection, conducted the analyses, and wrote the manuscript. SWH and GOR delivered the intervention and assisted with manuscript writing. A-MV conceptualized the study and guided manuscript preparation. All authors reviewed and agreed with the final manuscript prior to submission.

Funding None.

Data Availability None.

Code Availability None.

\section{Declarations}

Conflict of interest All authors declare that they have no conflicts of interest.

Ethical Approval Partners Healthcare Human Research Committee has approved the procedures (IRB \# 2020P003067 and 2020P004087).

Consent to Participate All participants provided written informed consent. 
Consent for Publication All participants consented to the publication of anonymized data.

\section{References}

Advocat, J., Enticott, J., Vandenberg, B., Hassed, C., Hester, J., \& Russell, G. (2016). The effects of a mindfulness-based lifestyle program for adults with Parkinson's disease: A mixed methods, wait list controlled randomised control study. BMC Neurology, 16, 166. https://doi.org/10.1186/s12883-016-0685-1

Ahlskog, J. E., Geda, Y. E., Graff-Radford, N. R., \& Petersen, R. C. (2011). Physical exercise as a preventive or disease-modifying treatment of dementia and brain aging. Mayo Clinic Proceedings, 86, 876-884. https://doi.org/10.4065/mcp.2011.0252

Allan, C. L., Behrman, S., Ebmeier, K. P., \& Valkanova, V. (2017). Diagnosing early cognitive decline-When, how and for whom? Maturitas, 96, 103-108. https://doi.org/10.1016/j.maturitas.2016. 11.018

Amireault, S., \& Godin, G. (2015). The Godin-Shephard leisure-time physical activity questionnaire: Validity evidence supporting its use for classifying healthy adults into active and insufficiently active categories. Perceptual and Motor Skills, 120, 604-622. https://doi.org/10.2466/03.27.PMS.120v19x7

Andel, R., Crowe, M., Pedersen, N. L., Fratiglioni, L., Johansson, B., \& Gatz, M. (2008). Physical exercise at midlife and risk of dementia three decades later: A population-based study of Swedish twins. The Journals of Gerontology. Series A, Biological Sciences and Medical Sciences, 63, 62-66.

Andrieu, S., Guyonnet, S., Coley, N., Cantet, C., Bonnefoy, M., Bordes, S., Bories, L., Cufi, M.-N., Dantoine, T., Dartigues, J.-F., Desclaux, F., Gabelle, A., Gasnier, Y., Pesce, A., Sudres, K., Touchon, J., Robert, P., Rouaud, O., Legrand, P., ... Olivier-Abbal, P. (2017). Effect of long-term omega 3 polyunsaturated fatty acid supplementation with or without multidomain intervention on cognitive function in elderly adults with memory complaints (MAPT): A randomised, placebo-controlled trial. The Lancet Neurology, 16, 377-389. https://doi.org/10.1016/S1474-4422(17) 30040-6

Ashford, J. W., \& Mortimer, J. A. (2002). Non-familial Alzheimer's disease is mainly due to genetic factors. Journal of Alzheimer's Disease: JAD, 4, 169-177.

Attkisson, C.C. (1987). Client satisfaction questionnaire (CSQ-8). In K. Corcoran \& K. Fischer (Eds.), Measures for clinical practice: A sourcebook (Vol. 2, 3rd Ed.). New York: Free Press.

Barnard, Y., Bradley, M. D., Hodgson, F., \& Lloyd, A. D. (2013). Learning to use new technologies by older adults: Perceived difficulties, experimentation behaviour and usability. Computers in Human Behavior, 29, 1715-1724. https://doi.org/10.1016/j.chb. 2013.02.006

Barnes, D. E., \& Yaffe, K. (2011). The projected effect of risk factor reduction on Alzheimer's disease prevalence. The Lancet Neurology, 10, 819-828. https://doi.org/10.1016/S1474-4422(11) 70072-2

Barrett, S., Begg, S., O’Halloran, P., \& Kingsley, M. (2018). Integrated motivational interviewing and cognitive behaviour therapy for lifestyle mediators of overweight and obesity in community-dwelling adults: A systematic review and meta-analyses. BMC Public Health, 18, 1160. https://doi.org/10.1186/s12889-018-6062-9

Baumgart, M., Snyder, H. M., Carrillo, M. C., Fazio, S., Kim, H., \& Johns, H. (2015). Summary of the evidence on modifiable risk factors for cognitive decline and dementia: A populationbased perspective. Alzheimer's \& Dementia: The Journal of the
Alzheimer's Association, 11, 718-726. https://doi.org/10.1016/j. jalz.2015.05.016

Belleville, S., Nygaard, H. B., Bherer, L., Camicioli, R., Carrier, J., Anderson, N. D., Dang-Vu, T. T., Dwosh, E., Ferland, G., Harris, E., Laurin, D., Liu-Ambrose, T., Madlensky, L., Miller, L., Montero-Odasso, M., Phillips, N., Pichora-Fuller, M. K., Robillard, J., Smith, E. E., ... Feldman, H. H. (2020). The Brain Health Support Program: A web-based interactive platform to increase dementia literacy and awareness regarding lifestyle factors in atrisk individuals. Alzheimer's \& Dementia, 16, e042603. https:// doi.org/10.1002/alz.042603

Brawley, L. R., Rejeski, W. J., \& King, A. C. (2003). Promoting physical activity for older adults: The challenges for changing behavior. American Journal of Preventive Medicine, 25, 172-183. https:// doi.org/10.1016/s0749-3797(03)00182-x

Brookmeyer, R., Johnson, E., Ziegler-Graham, K., \& Arrighi, H. M. (2007). Forecasting the global burden of Alzheimer's disease. Alzheimer's \& Dementia: The Journal of the Alzheimer's Association, 3, 186-191. https://doi.org/10.1016/j.jalz.2007.04.381

Bush, K., Kivlahan, D. R., McDonell, M. B., Fihn, S. D., \& Bradley, K. A. (1998). The AUDIT alcohol consumption questions (AUDITC): An effective brief screening test for problem drinking. Ambulatory Care Quality Improvement Project (ACQUIP). Alcohol use disorders identification test. Archives of Internal Medicine, 158, 1789-1795. https://doi.org/10.1001/archinte.158.16.1789

Buysse, D. J., Reynolds, C. F., Monk, T. H., Berman, S. R., \& Kupfer, D. J. (1989). The Pittsburgh Sleep Quality Index: A new instrument for psychiatric practice and research. Psychiatry Research, 28, 193-213. https://doi.org/10.1016/0165-1781(89)90047-4

Cadar, D., Pikhart, H., Mishra, G., Stephen, A., Kuh, D., \& Richards, M. (2012). The role of lifestyle behaviors on 20-year cognitive decline. Journal of Aging Research, 2012, 1-13. https://doi.org/ 10.1155/2012/304014

Cations, M., Radisic, G., Crotty, M., \& Laver, K. E. (2018). What does the general public understand about prevention and treatment of dementia? A systematic review of population-based surveys. PLoS ONE, 13, e0196085. https://doi.org/10.1371/journal.pone. 0196085

Cella, D., Riley, W., Stone, A., Rothrock, N., Reeve, B., Yount, S., Amtmann, D., Bode, R., Buysse, D., Choi, S., Cook, K., Devellis, R., DeWalt, D., Fries, J. F., Gershon, R., Hahn, E. A., Lai, J.-S., Pilkonis, P., Revicki, D., ... PROMIS Cooperative Group. (2010). The Patient-Reported Outcomes Measurement Information System (PROMIS) developed and tested its first wave of adult self-reported health outcome item banks: 2005-2008. Journal of Clinical Epidemiology, 63, 1179-1194. https://doi.org/10.1016/j. jclinepi.2010.04.011

Cerwinske, L. A., Rasmussen, H. E., Lipson, S., Volgman, A. S., \& Tangney, C. C. (2017). Evaluation of a dietary screener: The Mediterranean Eating Pattern for Americans tool. Journal of Human Nutrition and Dietetics: The Official Journal of the British Dietetic Association, 30, 596-603. https://doi.org/10.1111/jhn.12451

Chaffin, A. J., \& Harlow, S. D. (2005). Cognitive learning applied to older adult learners and technology. Educational Gerontology, 31, 301-329. https://doi.org/10.1080/03601270590916803

Clark, F., Jackson, J., Carlson, M., Chou, C.-P., Cherry, B. J., JordanMarsh, M., Knight, B. G., Mandel, D., Blanchard, J., Granger, D. A., Wilcox, R. R., Lai, M. Y., White, B., Hay, J., Lam, C., Marterella, A., \& Azen, S. P. (2012). Effectiveness of a lifestyle intervention in promoting the well-being of independently living older people: Results of the well elderly 2 randomised controlled trial. Journal of Epidemiology and Community Health, 66, 782-790. https://doi.org/10.1136/jech.2009.099754

Claudia, C., Aguirre, E., Barber, J. A., Bass, N., Brodaty, H., Burton, A., Higgs, P., Abrams, R., Huntley, J., Lang, I., Kales, H. C., 
Marchant, N. L., Minihane, A. M., Ritchie, K., Morgan-Trimmer, S., Arvanitakis, Z., Walters, K., Wenborn, J., \& Rapaport, P. (2020). APPLE-Tree (Active Prevention in People at risk of dementia: Lifestyle, bEhaviour change and Technology to REducE cognitive and functional decline) programme: Protocol. International Journal of Geriatric Psychiatry, 35, 811-819. https://doi. org/10.1002/gps.5249

Cohen, S., Kamarck, T., \& Mermelstein, R. (1983). A global measure of perceived stress. Journal of Health and Social Behavior, 24, 385-396.

Constantino, M. J., Arnkoff, D. B., Glass, C. R., Ametrano, R. M., \& Smith, J. Z. (2011). Expectations. Journal of Clinical Psychology, 67, 184-192. https://doi.org/10.1002/jclp.20754

Devilly, G. J., \& Borkovec, T. D. (2000). Psychometric properties of the credibility/expectancy questionnaire. Journal of Behavior Therapy and Experimental Psychiatry, 31, 73-86.

Doorley, J. D., Mace, R. A., Popok, P. J., Grunberg, V. A., Ragnhildstveit, A., \& Vranceanu, A. M. (2021). Feasibility randomized controlled trial of a mind-body activity program for older adults with chronic pain and cognitive decline: The virtual "Active Brains" study. Gerontologist, 6, gnab135. https://doi.org/10.1093/geront/ gnab135

Dutton, G. (2008). The role of mindfulness in health behavior change. ACSM'S Health \& Fitness Journal, 12, 7-12. https://doi.org/10. 1249/FIT.0b013e31817bf5db

Eaton, K., Stritzke, W., \& Ohan, J. (2019). Using scribes in qualitative research as an alternative to transcription. The Qualitative Report, 24, 586-605. https://doi.org/10.46743/2160-3715/2019.3473

Ewers, M., Sperling, R. A., Klunk, W. E., Weiner, M. W., \& Hampel, H. (2011). Neuroimaging markers for the prediction and early diagnosis of Alzheimer's disease dementia. Trends in Neurosciences, 34, 430-442. https://doi.org/10.1016/j.tins.2011.05.005

Gale, R. C., Wu, J., Erhardt, T., Bounthavong, M., Reardon, C. M., Damschroder, L. J., \& Midboe, A. M. (2019). Comparison of rapid vs in-depth qualitative analytic methods from a process evaluation of academic detailing in the Veterans Health Administration. Implementation Science, 14, 11. https://doi.org/10.1186/ s13012-019-0853-y

Geda, Y. E., Roberts, R. O., Knopman, D. S., Christianson, T. J. H., Pankratz, V. S., Ivnik, R. J., Boeve, B. F., Tangalos, E. G., Petersen, R. C., \& Rocca, W. A. (2010). Physical exercise, aging, and mild cognitive impairment: A population-based study. Archives of Neurology. https://doi.org/10.1001/archneurol.2009. 297

Geiger, P. J., Boggero, I. A., Brake, C. A., Caldera, C. A., Combs, H. L., Peters, J. R., \& Baer, R. A. (2016). Mindfulness-based interventions for older adults: A review of the effects on physical and emotional well-being. Mindfulness, 7, 296-307. https://doi.org/ 10.1007/s12671-015-0444-1

Greenberg, J., Lin, A., Zale, E. L., Kulich, R. J., James, P., Millstein, R. A., Shapiro, H., Schatman, M. E., Edwards, R. R., \& Vranceanu, A.-M. (2019). Development and early feasibility testing of a mindbody physical activity program for patients with heterogeneous chronic pain; the getactive study. Journal of Pain Research, 12, 3279-3297. https://doi.org/10.2147/JPR.S222448

Hahn, E. A., DeWalt, D. A., Bode, R. K., Garcia, S. F., DeVellis, R. F., Correia, H., Cella, D., \& PROMIS Cooperative Group. (2014). New English and Spanish social health measures will facilitate evaluating health determinants. Health Psychology: Official Journal of the Division of Health Psychology, American Psychological Association, 33, 490-499. https://doi.org/10.1037/hea0000055

Hamer, M., \& Chida, Y. (2009). Physical activity and risk of neurodegenerative disease: A systematic review of prospective evidence. Psychological Medicine, 39, 3-11. https://doi.org/10.1017/S0033 291708003681
Hamilton, A. B., \& Finley, E. P. (2019). Qualitative methods in implementation research: An introduction. Psychiatry Research, 280, 112516. https://doi.org/10.1016/j.psychres.2019.112516

Heyn, P., Abreu, B. C., \& Ottenbacher, K. J. (2004). The effects of exercise training on elderly persons with cognitive impairment and dementia: A meta-analysis. Archives of Physical Medicine and Rehabilitation, 85, 1694-1704.

Jacobson, N. S., \& Truax, P. (1991). Clinical significance: A statistical approach to defining meaningful change in psychotherapy research. Journal of Consulting and Clinical Psychology, 59, $12-19$.

Jansen, W. J., Ossenkoppele, R., Knol, D. L., Tijms, B. M., Scheltens, P., Verhey, F. R. J., Visser, P. J., Aalten, P., Aarsland, D., Alcolea, D., Alexander, M., Almdahl, I. S., Arnold, S. E., Baldeiras, I., Barthel, H., Berckel, B. N. M. van, Bibeau, K., Blennow, K., Brooks, D. J., ... Zetterberg, H. (2015). Prevalence of cerebral amyloid pathology in persons without dementia: A meta-analysis. JAMA, 313, 1924-1938. https://doi.org/10.1001/jama.2015.4668

Janssen, V., De Gucht, V., Dusseldorp, E., \& Maes, S. (2013). Lifestyle modification programmes for patients with coronary heart disease: A systematic review and meta-analysis of randomized controlled trials. European Journal of Preventive Cardiology, 20, 620-640. https://doi.org/10.1177/2047487312462824

Jessen, F. (2014). Subjective and objective cognitive decline at the pre-dementia stage of Alzheimer's disease. European Archives of Psychiatry and Clinical Neuroscience, 264, S3-7. https://doi.org/ 10.1007/s00406-014-0539-z

Jessen, F., Amariglio, R. E., van Boxtel, M., Breteler, M., Ceccaldi, M., Chételat, G., Dubois, B., Dufouil, C., Ellis, K. A., van der Flier, W. M., Glodzik, L., van Harten, A. C., de Leon, M. J., McHugh, P., Mielke, M. M., Molinuevo, J. L., Mosconi, L., Osorio, R. S., Perrotin, A., ... Subjective Cognitive Decline Initiative (SCD-I) Working Group. (2014). A conceptual framework for research on subjective cognitive decline in preclinical Alzheimer's disease. Alzheimer's \& Dementia: The Journal of the Alzheimer's Association, 10, 844-852. https://doi.org/10.1016/j.jalz.2014.01.001

Lam, L.C.-W., Chan, W. C., Leung, T., Fung, A.W.-T., \& Leung, E.M.F. (2015). Would older adults with mild cognitive impairment adhere to and benefit from a structured lifestyle activity intervention to enhance cognition?: A cluster randomized controlled trial. PLoS ONE, 10, e0118173. https://doi.org/10.1371/journal. pone. 0118173

Langa, K. M., \& Levine, D. A. (2014). The diagnosis and management of mild cognitive impairment: A clinical review. JAMA, 312, 2551-2561. https://doi.org/10.1001/jama.2014.13806

Larson, E. B., Yaffe, K., \& Langa, K. M. (2013). New insights into the dementia epidemic. New England Journal of Medicine, 369, 2275-2277. https://doi.org/10.1056/NEJMp1311405

Livingston, G., Huntley, J., Sommerlad, A., Ames, D., Ballard, C., Banerjee, S., Brayne, C., Burns, A., Cohen-Mansfield, J., Cooper, C., Costafreda, S. G., Dias, A., Fox, N., Gitlin, L. N., Howard, R., Kales, H. C., Kivimäki, M., Larson, E. B., Ogunniyi, A., ... Mukadam, N. (2020). Dementia prevention, intervention, and care: 2020 report of the Lancet Commission. The Lancet, 396, 413-446. https://doi.org/10.1016/S0140-6736(20)30367-6

Lourida, I., Hannon, E., Littlejohns, T. J., Langa, K. M., Hyppönen, E., Kuźma, E., \& Llewellyn, D. J. (2019). Association of lifestyle and genetic risk with incidence of dementia. JAMA, 322, 430-437. https://doi.org/10.1001/jama.2019.9879

Ludwig, D. S., \& Kabat-Zinn, J. (2008). Mindfulness in medicine. JAMA, 300, 1350-1352. https://doi.org/10.1001/jama.300.11. 1350

Mace, R. A., Doorley, J. D., Popok, P. J., \& Vranceanu, A.-M. (2020). Live video adaptations to a mind-body activity program for chronic pain and cognitive decline: Protocol for the "Virtual 
Active Brains" study. JMIR Research Protocols. https://doi.org/ $10.2196 / 25351$

Mace, R. A., Gates, M. V., Bullard, B., Lester, E. G., Silverman, I. H., Quiroz, Y. T., \& Vranceanu, A.-M. (2020). Development of a novel mind-body activity and pain management program for older adults with cognitive decline. Gerontologist. https://doi.org/10. 1093/geront/gnaa084

Mace, R. A., Gates, M. V., Popok, P. J., Kulich, R., Quiroz, Y. T., \& Vranceanu, A.-M. (2020). Feasibility trial of a mind-body activity pain management program for older adults with cognitive decline. Gerontologist. https://doi.org/10.1093/geront/gnaa179

Mace, R., Greenberg, J., Stauder, M., Reynolds, G., \& Vranceanu, A. (2021). My Healthy Brain: A multimodal lifestyle program to promote brain health. Aging \& Mental Health. https://doi.org/10. 1080/13607863.2021.1904828

Mahaffey, B. L., Mackin, D. M., Vranceanu, A.-M., Lofaro, L., Bromet, E. J., Luft, B. J., \& Gonzalez, A. (2020). The Stony Brook Health Enhancement Program: The development of an active control condition for mind-body interventions. Journal of Health Psychology, 25(13-14), 2129-2140. https://doi.org/10.1177/13591 05318787024

McMaster, M., Kim, S., Clare, L., Torres, S. J., Cherbuin, N., D’Este, C., \& Anstey, K. J. (2020). Lifestyle risk factors and cognitive outcomes from the multidomain dementia risk reduction randomized controlled trial, body brain life for cognitive decline (BBL-CD). Journal of the American Geriatrics Society, 68, 2629-2637. https://doi.org/10.1111/jgs.16762

Mehta, D., Jackson, R., Paul, G., Shi, J., \& Sabbagh, M. (2017). Why do trials for Alzheimer's disease drugs keep failing? A discontinued drug perspective for 2010-2015. Expert Opinion on Investigational Drugs, 26, 735-739. https://doi.org/10.1080/13543784. 2017.1323868

Ngandu, T., Lehtisalo, J., Solomon, A., Levälahti, E., Ahtiluoto, S., Antikainen, R., Bäckman, L., Hänninen, T., Jula, A., Laatikainen, T., Lindström, J., Mangialasche, F., Paajanen, T., Pajala, S., Peltonen, M., Rauramaa, R., Stigsdotter-Neely, A., Strandberg, T., Tuomilehto, J., ... Kivipelto, M. (2015). A 2 year multidomain intervention of diet, exercise, cognitive training, and vascular risk monitoring versus control to prevent cognitive decline in at-risk elderly people (FINGER): A randomised controlled trial. Lancet (London, England), 385, 2255-2263. https://doi.org/10.1016/ S0140-6736(15)60461-5

Nissen, T., \& Wynn, R. (2014). The clinical case report: A review of its merits and limitations. BMC Research Notes, 7, 264. https:// doi.org/10.1186/1756-0500-7-264

Onken, L. S., Carroll, K. M., Shoham, V., Cuthbert, B. N., \& Riddle, M. (2014). Reenvisioning clinical science: Unifying the discipline to improve the public health. Clinical Psychological Science: A Journal of the Association for Psychological Science, 2, 22-34. https://doi.org/10.1177/2167702613497932

Pilkonis, P. A., Choi, S. W., Reise, S. P., Stover, A. M., Riley, W. T., \& Cella, D. (2011). Item banks for measuring emotional distress from the Patient-Reported Outcomes Measurement Information System (PROMIS®): Depression, anxiety, and anger. Assessment, 18, 263-283. https://doi.org/10.1177/1073191111411667

Pilkonis, P. A., Yu, L., Dodds, N. E., Johnston, K. L., Maihoefer, C. C., \& Lawrence, S. M. (2014). Validation of the depression item bank from the Patient-Reported Outcomes Measurement Information System (PROMIS) in a three-month observational study. Journal of Psychiatric Research, 56, 112-119. https://doi.org/10.1016/j. jpsychires.2014.05.010

Rabin, J. S., Klein, H., Kirn, D. R., Schultz, A. P., Yang, H.-S., Hampton, O., Jiang, S., Buckley, R. F., Viswanathan, A., Hedden, T., Pruzin, J., Yau, W.-Y.W., Guzmán-Vélez, E., Quiroz, Y. T., Properzi, M., Marshall, G. A., Rentz, D. M., Johnson, K. A., Sperling,
R. A., \& Chhatwal, J. P. (2019). Associations of physical activity and $\beta$-amyloid with longitudinal cognition and neurodegeneration in clinically normal older adults. JAMA Neurology, 76, 12031210. https://doi.org/10.1001/jamaneurol.2019.1879

Raina, P., Santaguida, P., Ismaila, A., Patterson, C., Cowan, D., Levine, M., Booker, L., \& Oremus, M. (2008). Effectiveness of cholinesterase inhibitors and memantine for treating dementia: Evidence review for a clinical practice guideline. Annals of Internal Medicine, 148, 379-397. https://doi.org/10.7326/0003-4819-148-5200803040-00009

Renfro, C. P., Rome, Z., Gatwood, J., \& Hohmeier, K. C. (2021). Use of rapid assessment procedures when analyzing qualitative data in pharmacy research. Research in Social and Administrative Pharmacy. https://doi.org/10.1016/j.sapharm.2021.05.013

Reuter-Lorenz, P. A., \& Park, D. C. (2014). How does it STAC up? Revisiting the scaffolding theory of aging and cognition. Neuropsychology Review, 24, 355-370. https://doi.org/10.1007/ s11065-014-9270-9

Rose, M., Bjorner, J. B., Becker, J., Fries, J. F., \& Ware, J. E. (2008). Evaluation of a preliminary physical function item bank supported the expected advantages of the Patient-Reported Outcomes Measurement Information System (PROMIS). Journal of Clinical Epidemiology, 61, 17-33. https://doi.org/10.1016/j.jclinepi.2006.06. 025

Sabayan, B., \& Sorond, F. (2017). Reducing risk of dementia in older age. JAMA, 317, 2028-2028. https://doi.org/10.1001/jama.2017. 2247

Schulte, D. (2008). Patients' outcome expectancies and their impression of suitability as predictors of treatment outcome. Psychotherapy Research: Journal of the Society for Psychotherapy Research, 18, 481-494. https://doi.org/10.1080/10503300801932505

Schuman-Olivier, Z., Trombka, M., Lovas, D. A., Brewer, J. A., Vago, D. R., Gawande, R., Dunne, J. P., Lazar, S. W., Loucks, E. B., \& Fulwiler, C. (2020). Mindfulness and behavior change. Harvard Review of Psychiatry, 28, 371-394. https://doi.org/10.1097/HRP. 0000000000000277

Shaha, M., Wenzel, J., \& Hill, E. E. (2011). Planning and conducting focus group research with nurses. Nurse Researcher, 18, 77-87. https://doi.org/10.7748/nr2011.01.18.2.77.c8286

Sink, K. M., Holden, K. F., \& Yaffe, K. (2005). Pharmacological treatment of neuropsychiatric symptoms of dementia: A review of the evidence. JAMA, 293, 596. https://doi.org/10.1001/jama.293.5. 596

Slooter, A. J., Cruts, M., Kalmijn, S., Hofman, A., Breteler, M. M., Van Broeckhoven, C., \& van Duijn, C. M. (1998). Risk estimates of dementia by apolipoprotein $\mathrm{E}$ genotypes from a population-based incidence study: The Rotterdam Study. Archives of Neurology, 55, 964-968.

SPRINT MIND Investigators for the SPRINT Research Group, Williamson, J. D., Pajewski, N. M., Auchus, A. P., Bryan, R. N., Chelune, G., Cheung, A. K., Cleveland, M. L., Coker, L. H., Crowe, M. G., Cushman, W. C., Cutler, J. A., Davatzikos, C., Desiderio, L., Erus, G., Fine, L. J., Gaussoin, S. A., Harris, D., Hsieh, M.-K., ... Wright, C. B. (2019). Effect of intensive vs standard blood pressure control on probable dementia: A randomized clinical trial. JAMA, 321, 553-561. https://doi.org/10.1001/jama.2018. 21442

Sullivan, A. N., \& Lachman, M. E. (2017). Behavior change with fitness technology in sedentary adults: A review of the evidence for increasing physical activity. Frontiers in Public Health. https:// doi.org/10.3389/fpubh.2016.00289

Tomaszewski Farias, S., Mungas, D., Harvey, D. J., Simmons, A., Reed, B. R., \& Decarli, C. (2011). The measurement of everyday cognition: Development and validation of a short form of the Everyday Cognition scales. Alzheimer's \& Dementia: The Journal of 
the Alzheimer's Association, 7, 593-601. https://doi.org/10.1016/j. jalz.2011.02.007

Tsai, H.-Y.S., Shillair, R., \& Cotten, S. R. (2017). Social support and "playing around": An examination of how older adults acquire digital literacy with tablet computers. Journal of Applied Gerontology: The Official Journal of the Southern Gerontological Society, 36, 29-55. https://doi.org/10.1177/0733464815609440

Tuso, P. (2015). Strategies to increase physical activity. The Permanente Journal, 19, 84-88. https://doi.org/10.7812/TPP/14-242

Verlinden, V. J. A., van der Geest, J. N., de Bruijn, R. F. A. G., Hofman, A., Koudstaal, P. J., \& Ikram, M. A. (2016). Trajectories of decline in cognition and daily functioning in preclinical dementia. Alzheimer's \& Dementia: The Journal of the Alzheimer's Association, 12, 144-153. https://doi.org/10.1016/j.jalz.2015.08.001

White, N. D., Lenz, T. L., \& Smith, K. (2013). Tool guide for lifestyle behavior change in a cardiovascular risk reduction program. Psychology Research and Behavior Management, 6, 55-63. https:// doi.org/10.2147/PRBM.S40490

Whitmer, R. A., Sidney, S., Selby, J., Johnston, S. C., \& Yaffe, K. (2005). Midlife cardiovascular risk factors and risk of dementia in late life. Neurology, 64, 277-281. https://doi.org/10.1212/01. WNL.0000149519.47454.F2

Xu, W., Tan, L., Wang, H.-F., Jiang, T., Tan, M.-S., Tan, L., Zhao, Q.-F., Li, J.-Q., Wang, J., \& Yu, J.-T. (2015). Meta-analysis of modifiable risk factors for Alzheimer's disease. Journal of Neurology, Neurosurgery \& Psychiatry. https://doi.org/10.1136/ jnnp-2015-310548

Goossens, M. E. J. B., Vlaeyen, J. W. S., Hidding, A., Kole-Snijders, A., \& Evers, S. M. A. A. (2005). Treatment expectancy affects the outcome of cognitive-behavioral interventions in chronic pain. The Clinical Journal of Pain, 21, 18-26; discussion 69-72. https:// doi.org/10.1097/00002508-200501000-00003
Merriam, S. B., Caffarella, R. S., \& Baumgartner, L. (2012). Learning in adulthood: A comprehensive guide. Wiley.

Rosenbloom, M., Borson, S., Barclay, T., Hanson, L. R., Werner, A., Stuck, L., \& McCarten, J. (2016). Routine cognitive screening in a neurology practice. Neurology: Clinical Practice, 6, 16-21. https://doi.org/10.1212/CPJ.0000000000000186

Rubin, H. J., \& Rubin, I. S. (2005). Qualitative interviewing (2nd ed.): The art of hearing data (2nd ed.). SAGE Publications, Inc. https:// doi.org/10.4135/9781452226651

Taylor, B., Henshall, C., Kenyon, S., Litchfield, I., \& Greenfield, S. (2018). Can rapid approaches to qualitative analysis deliver timely, valid findings to clinical leaders? A mixed methods study comparing rapid and thematic analysis. BMJ Open. https://doi. org/10.1136/bmjopen-2017-019993

Vranceanu, A.-M., Zale, E. L., Funes, C. J., Macklin, E. A., McCurley, J., Park, E. R., Jordan, J. T., Lin, A., \& Plotkin, S. R. (2018). Mind-body treatment for international english-speaking adults with neurofibromatosis via live videoconferencing: Protocol for a single-blind randomized controlled trial. JMIR Research Protocols, 7(10), e11008. https://doi.org/10.2196/11008

World Health Organization. (2017). Global action plan on the public health response to dementia 2017-2025 (p. 44). https://www.who. int/publications/i/item/global-action-plan-on-the-public-healthresponse-to-dementia-2017---2025

Publisher's Note Springer Nature remains neutral with regard to jurisdictional claims in published maps and institutional affiliations. 